\title{
TRIAGE OF PERFORATIVE PERITONITIS
}

\author{
Kanwar Singh Goel1 ${ }^{1}$ Sapna Goel²
}

${ }^{1}$ Senior Surgeon, Department of Surgery, Maharaja Agrasen Hospital, Jind, Haryana.

${ }^{2}$ Ex. Senior Resident, BGS Government of Surgery Medical College for Women, Khanpur Kalan, Sonepat, Haryana.

\section{ABSTRACT}

\section{BACKGROUND}

Emergencies like perforative peritonitis present in various clinical forms ranging from early presentation to presentation in septic shock state. An indigenous system based on important clinical parameters, haematology and biochemical profile of patients which can help in segregating serious cases which in turn can be referred to advanced centres should be devised. Chest and cardiac evaluation have been given veto powers. This means that even if other criteria suggest that patient should be taken in and chest/cardiac evaluation shows high risk, the case is referred to higher centre. The objective criteria are in evolving stage and brought to readership through this article for further improvement based on individual's experience.

Aim is to use an objective criteria or algorithm which could help in segregating and selecting right cases of abdominal emergencies, particularly perforating peritonitis, so that mortality is avoided by taking up a wrong case (which cannot be treated at such an under-resourced centre).

\section{MATERIALS AND METHODS}

Although, there are several scoring systems available for severe peritonitis, but over last 10 years 256 cases of perforation peritonitis coming to Maharaja Agrasen Hospital, Jind, formed the material of study. All patients were screened through following parameters e. g. age, dehydration, pulse/B.P., urine output, haemoglobin, s. albumin, blood urea, s. creatinine, s. sodium, s. potassium. Based on these parameters, patients were divided into Category I and II. Category I patients were retained for further management at the peripheral centres, while Category II patients were subjected to resuscitation by intravenous fluids, blood, antibiotics, etc. for 4 hours. All the parameters as above were again evaluated after 4 hours and if the patient moved to Category I it was retained for further management, otherwise it was referred to a tertiary care centre.

\section{RESULTS}

After applying all these criteria, initially 190 patients were found to belong to Category I, while 66 to Category II (Table 1). These 66 patients were subjected to intensive resuscitation and monitoring and re-evaluation was done after 4 hours. As a result of resuscitation 13 patients had climbed to Category I, while 53 still remained in Category II. All these 53 patients were referred to a tertiary care centre. All the 203 patients who were taken were subjected to exploratory laparotomy where relevant pathology was appropriately dealt, i.e. closure of duodenal perforation or enteric perforation, etc. Thus, we see that majority of the patients had duodenal perforation and enteric perforations. There were 2 patients having uterine perforations. In the present series, the mortality is nil because of selection criteria of taking in the patient in a peripheral under-resourced centre. Superficial wound dehiscence and stitch sepsis were the most common complications in the present series.

\section{CONCLUSION}

By applying objective criteria for segregating serious illnesses requiring surgical intervention, e.g. perforative peritonitis, it would be a good idea to segregate more serious cases right at the outset, maximum within 4 hours of admission and this can be termed as triage of non-traumatic serious cases. The zero mortality in the present study is another evidence to indicate that if cases are properly selected keeping in mind the limitations and lack of resources of peripheral centres, a good care can be given to those who fit into the facilities available at that centre.

\section{KEYWORDS}

Triage, Peritonitis, Peripheral Hospital.

HOW TO CITE THIS ARTICLE: Goel KS, Goel S. Triage of perforative peritonitis. J. Evolution Med. Dent. Sci. 2016;5(90):6698-6701, DOI: $10.14260 /$ jemds/2016/1515

Financial or Other, Competing Interest: None.

Submission 21-10-2016, Peer Review 03-11-2016,

Acceptance 05-11-2016, Published 09-11-2016.

Corresponding Author:

Dr. Kanwar Singh Goel,

Ex. Flight Lieutenant, Indian Air Force,

Maharaja Agrasen Hospital,

\#25/6, Opp. Bal Bhawan,

Gandhi Nagar, Scheme No. 6, Jind.

E-mail: dr.kanwarsinghgoel@rediffmail.com

DOI: $10.14260 /$ jemds/2016/1515

\section{BACKGROUND}

Abdominal emergencies are common in surgical practice. The lethality still remains high(1) and has been studied by modern statistical analysis also.(2) Many patients land in severe toxic state with delayed diagnosis and treatment.(3) Presence of pus and faecal material adversely affects mortality.(4) The volume of abdominal emergencies is so large that all these patients do not go to tertiary care centre, because of logistics prevailing in India.

Moreover, tertiary care centres may not be able to deal with such a large volume in view of the limit of their capacity facilities and manpower. Last few decades have seen upgradation of clinical working and surgical profile of serious 
cases coming to peripheral centres, which are not as equipped as tertiary care centres and are able to share a significant load of such cases.

These peripheral centres all though under-resourced can tackle serious abdominal emergencies, but it is difficult to provide surgicare to all such cases. Hence, realising the strength and weaknesses of peripheral centres, the author decided to use an objective criteria or algorithm which could help in segregating and selecting right cases of abdominal emergencies, particularly perforating peritonitis so that mortality is avoided by taking up a wrong case (which cannot be treated at such an under-resourced centre). The cases which are beyond the purview of management of the peripheral centres are referred to a tertiary care centre. The author has realised that by adopting such an objective policy, the unnecessary load of routine cases or cases which can be managed at peripheral level will be filtered and not put undue load on a tertiary care centre. This policy of segregating serious patients (which are to be referred to a tertiary care centre) is also advantageous to prevent any outrage, damage to hospital and manhandling of health care professionals because otherwise any mortality in serious abdominal emergencies is impulsively reacted by the attendants.

This article elaborates the objective parameters on which patients are segregated and the author has found it useful particularly over last decade.

\section{MATERIALS AND METHODS}

Although, there are several scoring systems available for severe peritonitis,(5) but over last 10 years 256 cases of perforation peritonitis coming to Maharaja Agrasen Hospital, Jind, formed the material of study. All patients were screened through following parameters.

\begin{tabular}{|c|c|c|c|}
\hline Sl. No. & Parameters & Favourable & Unfavourable \\
\hline 1 & Age & $<50$ yrs. & $>50$ yrs. \\
\hline 2 & Dehydration & Nil & Present \\
\hline 3 & Pulse/B.P. & $90 /$ normal & $\begin{array}{c}>90 / \text { systolic } \\
\text { hypotension }\end{array}$ \\
\hline 4 & Urine output & Normal & Decreased \\
\hline 5 & Haemoglobin & $<9$ & $>9$ \\
\hline 6 & S. Albumin & Normal & Decreased \\
\hline 7 & Blood urea & Normal & Raised \\
\hline 8 & S. creatinine & Normal & Raised \\
\hline 9 & S. sodium & Normal & Decreased \\
\hline 10 & S. potassium & Normal & $\begin{array}{c}\text { Hypo/Hyperka } \\
\text { laemia }\end{array}$ \\
\hline
\end{tabular}

These parameters were evolved by a pilot study, where it was found that these parameters play a role in making decision of segregation of serious cases. All the patients were subjected to above 10 parameters and were finally grouped into 2 categories.

1. Category I - where $\leq 4$ parameters were positive

2. Category II - where $>4$ parameters were positive, importance being given to urine output, S. albumin, blood urea and haemoglobin.

However, the clinical assessment of chest along with chest $\mathrm{x}$-ray and cardiac assessment along with ECG were given veto power. By veto power it is meant that if clinical assessment of chest and chest x-ray were normal as informed by the physician, patient was taken in otherwise referred to a tertiary care centre even if it belonged to Category I. Similarly, if cardiac status and ECG were normal as informed by the physician, the case was taken in otherwise referred to a tertiary care centre even if it belonged to Category I.

Based on categorisation as mentioned in table above Category I patients were retained for further management at the peripheral centres, while Category II patients were subjected to resuscitation by intravenous fluids, blood, antibiotics, etc. for 4 hours.

All the parameters as listed in the table above were again evaluated after 4 hours and if the patient moved to Category I it was retained for further management, otherwise it was referred to a tertiary care centre.

We did not take blood gas analysis during our assessment at peripheral centres, because this facility is not available.

\section{RESULTS}

After applying all these criteria initially 190 patients were found to belong to Category I, while 66 to Category II (Table 1). These 66 patients were subjected to intensive resuscitation and monitoring and re-evaluation was done after 4 hours. As a result of resuscitation 13 patients had climbed to Category I, while 53 still remained in Category II (Table 2). All these 53 patients were referred to a tertiary care centre and detailed analysis of these 53 patients showed that 9 patients belonged to veto criteria, i.e. in 3 patients, chest condition and/or chest $\mathrm{x}$-ray was not optimal and were labelled by physician as very high risk patients. Another 6 patients were found to be extremely high risk on cardiac and ECG evaluation. These patients had either history of recent myocardial infarction or unstable angina or varying degrees of heart blocks or some kind of arrhythmia (Table 3). In fact these 9 patients were also subjected to intensive resuscitation, which was actually uncalled for. Resuscitation should have been given only to 44 patients. But this overlap on 9 patients of veto criteria occurred because opinions of physicians after complete evaluation was available in 2-3 hours of start of resuscitation. Majority patients of Category II had 8 positive criteria (22 patients) followed by 18 patients having 7 positive criteria; 2 patients each had 5 and 6 positive criteria (Table 3).

All the 203 patients who were taken in (Table 4) were subjected to exploratory laparotomy where relevant pathology was appropriately dealt, i.e. closure of duodenal perforation or enteric perforation, etc. This was followed by a thorough peritoneal lavage and putting in abdominal drains. All the operated cases of peritonitis were given standard postoperative treatment consisting of nil per orally, Ryle's tube aspiration, IV fluids, IV antibiotics (Cephalosporin gen III, aminoglycosides and metronidazole), continuous oxygen for minimum 24 hours and analgesics. Once the patient passes flatus, Ryle's tube aspiration decreased to $100-150 \mathrm{~mL}$ and the colour of Ryle's tube aspirate became that of gastric juice, the Ryle's tube was removed and they were allowed orally. Early ambulation was our policy and stitches were removed on $12^{\text {th }}-14^{\text {th }}$ day. Those showing evidence of burst abdomen on $3^{\text {rd }}$ to $5^{\text {th }}$ postoperative day in the form of copious serous discharge were taken up for emergency secondary suturing. Any superficial dehiscence encountered during post-operative periods or after removal of stitches was dealt appropriately.

The operative findings of 203 operated patients are depicted in Table 5. Thus, we see that majority of the patients 
had duodenal perforation and enteric perforations. There were 2 patients having uterine perforations. In the present series, the mortality is nil because of selection criteria of taking in the patient in a peripheral under-resourced centre. The morbidity in form of various complications is depicted in Table 6. Superficial wound dehiscence and stitch sepsis were the most common complications in the present series.

\begin{tabular}{|c|c|}
\hline Category & Number of Patients \\
\hline I & 190 \\
\hline II & 66 \\
\hline Table 1. Showing Categorisation, $\mathbf{n = 2 5 6}$ \\
\hline
\end{tabular}

\begin{tabular}{|c|c|}
\hline Category & Number of Patients \\
\hline I & 13 \\
\hline II & 44 \\
\hline Veto criteria & 9 \\
\hline
\end{tabular}

Table 2. Showing Categorisation after Resuscitation, $n=66$

\begin{tabular}{|c|c|c|}
\hline Parameters & Criteria & $\begin{array}{c}\text { Number of } \\
\text { Patients }\end{array}$ \\
\hline \multirow{2}{*}{ Veto } & Veto Chest & 3 \\
\cline { 2 - 3 } & Veto Cardiac & 6 \\
\hline \multirow{3}{*}{$\begin{array}{c}\text { Category } \\
\text { Parameters }\end{array}$} & $>5$ positive & 2 \\
\cline { 2 - 3 } & $>6$ positive & 2 \\
\cline { 2 - 3 } & $>7$ positive & 18 \\
\cline { 2 - 3 } & $>8$ positive & 22 \\
\hline \multicolumn{2}{|c|}{ Table 3. Showing Details of Referred Cases, $\boldsymbol{n}=\mathbf{5 3}$} \\
\hline
\end{tabular}

\begin{tabular}{|c|c|}
\hline Category & Number of Patients \\
\hline I & 203 \\
\hline II & 53 \\
\hline Table 4. Showing Final Intake and Referral of Cases, $\mathbf{n = 2 5 6}$ \\
\hline
\end{tabular}

\begin{tabular}{|c|c|}
\hline Pathology & Number of Cases \\
\hline Duodenal perforation & 95 \\
\hline Enteric perforation & 88 \\
\hline Appendicular perforation & 18 \\
\hline Uterine perforation & 2 \\
\hline \multicolumn{2}{|c|}{$\begin{array}{l}\text { Table 5. Showing Profile of Operative } \\
\text { Pathology in Operated Cases, } n=203\end{array}$} \\
\hline
\end{tabular}

\begin{tabular}{|c|c|}
\hline Complication/Morbidity & Number of Patients \\
\hline Burst abdomen & 9 \\
\hline Superficial dehiscence & 43 \\
\hline Stitch sepsis & 25 \\
\hline Urinary tract infection & 9 \\
\hline Superficial thrombophlebitis & 17 \\
\hline Faecal fistula & 0 \\
\hline Table 6. Showing Morbidity Profile, $\boldsymbol{n}=\mathbf{2 0 3}$ \\
\hline
\end{tabular}

\section{DISCUSSION}

Indian subcontinent is a developing country where health care delivery system still needs upgradation. By various statistical data released by Government of India, the doctor population of India is far from expected level; $70 \%$ of the population of this country resides in rural area and does not have prompt and good access to even specialist care, what to say of super specialist services. Cost of medicare of metro cities and corporate hospitals is a prohibitive factor for poor and rural population. Although, steps are being taken at Government level and efforts are going for improving health care delivery to the last mean in the queue, yet the gap cannot be allowed to remain unfulfilled in wait of development of the entire system. It is because of these reasons that health care centres in class II and III towns in India have to take lead. As already said, the entire load of serious illnesses requiring surgical intervention like perforative peritonitis cannot be taken by tertiary care centres for obvious limitations of the hospital and population both. The peripheral centres have to play a big role to fulfil the above gap by providing health services at a lower cost. But at the same time, these peripheral centres are not as fully developed and well equipped and have to seek the help of advanced/tertiary care/higher centres. In such a situation if some objective criteria is applied for segregating serious illnesses requiring surgical intervention, e.g. perforative peritonitis following things can be achieved.

1. Avoidance of unnecessary mortality by directing very high risk cases directly to tertiary care centres, rather than referring them at a later stage from peripheral centres.

2. In the eventuality of death of such serious cases at peripheral centres (not referred to higher centres), emotionally charged relatives and attendants go on rampage, damage and destroy the hospital property and building and manhandle the healthcare professionals. These problems get compounded if legal remedy is sought for such criminal activities. These all can be avoided by following our policy of referring based on objective criteria.

3. Triage of serious cases like perforative peritonitis will reduce undue case load on tertiary care centres allowing clinicians of such centres to really focus on limited serious cases.

By the results in the present study it would be a good idea to segregate more serious cases right at the outset, maximum within 4 hours of admission and this can be termed as triage of non-traumatic serious cases. Despite huge advances in diagnostics, antibiotics and monitoring, the mortality still remains very high.(6) The zero mortality in the present study is another evidence to indicate that if cases are properly selected keeping in mind the limitations and lack of resources of peripheral centres, a good care can be given to those who fit into the facilities available at that centre. The complications encountered in the present series (Table 6) are important causes of prolonged hospitalisation and significant action requires to be taken for them to reduce the duration of hospitalisation.

Although, the criteria adopted in the present study are still in evolving stage yet remain very useful to as of now for peripheral centres as a single significant measure to reduce mortality. Continued analysis of various factors from various high volume peripheral centres, encountering such cases can result into evolution of better/addition criteria. Needless to say, study involving large number of cases is required to further improve on the scoring system so that perfect triage is done and mortality is brought to zero in under-resourced, under-privileged and not so well equipped peripheral centres. 


\section{REFERENCES}

1. Mattingly SS, Ram MD, Griffen WO. Factors influencing morbidity and mortality in perforated duodenal ulcer. Am J Surg 1980;46(2):61-6.

2. Boey J, Wong J, Ong GB. A prospective study of operative risk factors in perforated duodenal ulcers. Ann Surg 1982;195(3):265-9.

3. Santillana M. Surgical complications of typhoid fever: enteric perforation. World J Surg 1991;15(2):170-5.
4. Adesunkanmi AR, Ajao OG. The Prognostic factors in typhoid ileal perforation: a prospective study of 50 patients. J R Coll Surg Edinb 1997;42(6):395-9.

5. Ohmann C, Wittmann DH, Wacha H. Prospective evaluation of prognostic scoring systems in peritonitis. Peritonitis Study Group. Eur J Surg 1993;159(5):267-74.

6. Biondo S, Ramos E, Deiros M, et al. Prognostic factors for mortality in left colonic peritonitis: a new scoring system. J Am Coll Surg 2000;191(6):635-42. 